\title{
ANÁLISIS ÉTICO, RACIONALIDAD Y DISTRIBUCIÓN PÚBLICA
}

\author{
Jesús Antonio Serrano \\ Universidad Pontificia de México
}

\section{Resumen}

El artículo propone una manera en que el análisis de políticas públicas puede responder a la necesidad de construir el bien común, objetivo político que requiere valerse de políticas públicas como medios que promuevan la producción de bienes, lo que implica un ejercicio de racionalización de utilidades, que en materia política enfrenta el problema de salir avante del proceso de deliberación y construcción de la agenda política, la dificultad de elegir en condiciones de información incompleta y la dificultad de distribuir equitativamente cargas y beneficios. El artículo ejemplifica estas dificultades analizando las tendencias de generación y distribución de riqueza en América Latina.

\section{Palabras clave}

Políticas públicas, ética política, utilidad, distribución, justicia

\begin{abstract}
This paper propose how the public policy analysis contributes to build the common good, political aim that requires public policies as means to foster production of goods, as a utility maximization task. In politics, this exercise enfaces at least three major problems: how to go beyond the deliberation process and to construct the public agenda, how to do optimal choices whit incomplete information and how to distribute burdens and benefits in an equitable basis. Finally, we show this questions analysing the trends of production and distribution of wealth in Latin America.
\end{abstract}

\section{Key words}

Public policy, political ethics, utility, distribution, justice 


\section{Exposición}

El estudio de las reglas de elección racional orientadas a la maximización de los beneficios esperados no es nuevo, como tampoco lo es la reflexión crítica sobre la distribución de los beneficios derivados de la acción colectiva. Ríos de tinta han corrido en el intento de reconciliar ambas dimensiones en una propuesta congruente con la necesidad de mejorar la satisfacción de las necesidades humanas pero sensible a las cuestiones éticas relativas a un trato justo a las personas. Entonces, no pretendo la introducción de impresionantes hallazgos, pero sí abrir espacio a una reflexión que no ha sido tan abundante en América Latina, ya que las preocupaciones de los filósofos políticos y éticos de la región, se ha enfocado más a la defensa de ciertos valores como determinantes de la estructura y dinámica sociales, ya sea la libertad o la igualdad. Justifico las líneas que presento a su escrutinio, amable lector(a), ya que el dilema no está resuelto, prevalece como un problema teórico práctico que afecta en forma real a todos los estados. Su originalidad radica en el estudio de este tema desde una óptica ética radical, es decir, que mantiene como objeto formal la moralidad del estudio de la problemática derivada de los mecanismos de racionalidad y distribución, lo que requiere la elaboración de una metodología ética propia para el análisis de las políticas públicas, tarea a la que me he abocado.

\section{El análisis de políticas públicas como una forma de filosofía política aplicada}

Los valores que componen el Estado político así como los bienes públicos exigen para su realización valerse de políticas públicas como medios. Defino las políticas públicas, siguiendo a O’Donnell y Oszlak como “un conjunto de acciones y omisiones que manifiestan una determinada modalidad de intervención del Estado en relación con una cuestión que concita la atención, interés o movilización de otros actores en la sociedad civil "'. Como se verá más adelante, en sí mismas las políticas públicas son resultado y modelan a su vez la distribución de cargas y beneficios socialmente relevantes en el ámbito público. De ahí que Luis F. Aguilar las considere un proceso, un curso de acción: "Una política no es sólo una decisión (por ejemplo, la decisión de no actuar). Es, ante todo acción, un conjunto de acciones”2.

El análisis de políticas públicas es una forma de filosofía política aplicada ${ }^{3}$, en virtud de que articula conceptos sustantivos con decisiones prácticas de política pública como:

- Un concepto y modelo del Estado

- Un concepto teórico práctico de la política

- Un concepto moral de la persona, sus derechos y obligaciones

1 G. O’Donnell y O. Oszlak, Estado y políticas estatales en América Latina: Hacia una estrategia de investigación (Buenos Aires: CLACSO, 1976) 25.

Luis F. Aguilar, "Estudio introductorio”, La hechura de las políticas (México: Miguel A. Porrúa) 25.

3 Cf. Charles Anderson, "Political Philosophy, Practical Reason and Policy Analysis", Confronting Values in Policy Analysis, eds. Fischer y Forester (Newbury Park: Sage, 1987). 
- Un conjunto de principios de juicio para la toma de decisiones políticas.

A diferencia de la filosofía política, el análisis de políticas públicas no pretende llegar a principios normativos para el Estado, sino juzgar qué principios deben prevalecer en la forma en que el Estado asume determinados asuntos públicos, considerando la pluralidad de concepciones de bien y objetivos diferentes de los actores sociales, que "no pueden ser reducidos a una misma regla"4.

El análisis de políticas públicas a diferencia de la ciencia política propone un sistema (o disciplina) de juicio político como una forma de razón práctica que deberá orientarse a mejores decisiones, mientras que la segunda se concentrará más bien en la legitimidad teórica de un sistema frente a otro ${ }^{5}$.

En cuanto a su primera acepción, el análisis parte de y construye un modelo formal de Estado, en el cual cobran sentido, en función de una serie de valores sociopolíticos preestablecidos, las prácticas políticas, esto es, la dinámica social mediante la cual se busca satisfacer las necesidades materiales y sustantivas del conjunto social mediante instituciones que asignan y distribuyen cargas $\mathrm{y}$ beneficios.

El signo característico de esta acepción es el dinamismo, puesto que las políticas públicas obedecen a los valores reconocidos por una sociedad en el tiempo presente bajo el supuesto de su reproducción a largo plazo, pero mantiene simultáneamente la pretensión de superarlos en el afán de conformar (shaping) el Estado del futuro. Existe una dimensión de conflicto que precisa de la capacidad política de deliberación, argumentación, razonabilidad y acuerdo en la acep- tación de objetivos y la movilización de recursos sociales para su obtención.

Es por esta última vertiente, la necesidad de comprometer voluntades y recursos para la realización de objetivos de interés público, que el análisis de políticas públicas implica un concepto teórico-práctico de la política. La teoría política permite elaborar modelos instrumentales o de ingeniería institucional para entender y proponer los mejores mecanismos para la negociación de actores políticos, pero no satisface el aspecto material de los contenidos de esa negociación, por lo que se deja ver la necesidad de un mecanismo vinculante de ambas dimensiones. No prescinde de la negociación política, puesto que no es pura tecnocracia, pero tampoco olvida los aspectos técnicos requeridos para tomar decisiones con sentido.

En virtud de que el sentido de las decisiones siempre será el Estado en su conjunto y los ciudadanos (entendidos como personas poseedoras de derechos y obligaciones, sujetos de responsabilidad y capaces de movilizar sus recursos para obtener no sólo objetivos personales sino también comunes) entonces, el análisis de políticas públicas delimita un concepto moral de la persona, sus derechos y obligaciones, bajo la premisa de la doble implicación de obligaciones de la colectividad para con el individuo y de este para con la comunidad de la que forma parte.

Una dimensión destacada es la de desarrollar las capacidades metodológicas que permitan concluir decisiones técnicamente factibles y económicamente eficientes de entre aquellos objetivos de relevancia moral y política. En oposición a la aparente exclusión de estas dos dimensiones, el análisis de políticas públicas implica la integración consis-

$\begin{array}{ll}4 & \text { Cf. Anderson, “Political ...”, } 33 . \\ 5 & \text { Cf. Anderson, "Political ...”, } 34 .\end{array}$ 
tente de los objetivos morales que el Estado contempla para sí y los ciudadanos, con reglas de decisión que superen el idealismo de los filósofos centrados en el óptimo puro y no en el mejor de los posibles.

En virtud de su naturaleza teórico práctica, es decir político-técnica, el análisis de políticas públicas comprende la necesidad de articular el juicio prudente. La prudencia es la principal herramienta de la ética. Ya que se conoce el bien y se puede jerarquizar comparando diferentes aspectos de los bienes, el hecho es que en un mismo objeto coexisten diferentes aspectos y facetas de bien (útil, moral, estético, funcional, económico, etc.), y la posibilidad de elegir tomando en cuenta simultáneamente todas las facetas de bien presentes en el objeto, exige una capacidad especial, que es la prudencia.

La prudencia es una virtud, es decir un hábito, que consiste en elegir correctamente entre medios y fines. La prudencia es la virtud básica que nos permite conocer dónde está toda virtud.

En el ejercicio de nuestra capacidad de elección y decisión, se encuentra siempre la prudencia. Los dilemas morales, las mezclas de bien y mal o de diferentes ponderaciones de bondad en órdenes diferentes que caracterizan a los problemas prácticos, no podrían ser manejados sin la prudencia. De ahí que hablamos en todos estos casos de juicios y decisiones prudenciales, ya que se reconoce la complejidad de los problemas y se busca su mejor solución a la luz de los elementos relevantes a tomar en cuenta.
Esta dimensión prudencial que caracteriza las decisiones en función de la bondad que hace cada individuo, se encuentra amplificada y complejizada en el ámbito político dirigido a la realización del bien común.

\section{El bien común como objetivo de las políticas públicas}

Defino el bien común como el estado ideal de cosas que permite que las personas en lo individual, tanto como en el conjunto social, alcancen o tengan opción de alcanzar sus legítimos fines en un clima de libertades y respeto a sus derechos. El bien común es resultado de la agregación de satisfactores materiales en la vida civil ${ }^{6}$, aunque no se limita a éstos. Tales satisfactores requieren el trabajo o acción colectiva para alcanzar la producción de tales objetivos y bienes sociales.

El bien común se compone de una canasta de bienes comunes y privados accesibles a todas los ciudadanos, que pueden ser tangibles o intangibles, materiales y espirituales. El conjunto de bienestar o bien común es resultado de un esfuerzo de racionalización de los recursos disponibles para la satisfacción de las preferencias o valores, así como de un esfuerzo para asignar cargas y distribuir beneficios, ya que es falso el supuesto que cree que el disfrute del bien común es o debe ser igual para todos, puesto que hay facetas que sólo se pueden producir por el talento de un individuo y otras que pueden o no ser disfrutadas por alguna persona de acuerdo a su concepción del placer o del bien.

$6 \quad$ El bien común también se compone de todas aquellas producciones humanas de índole privada, como el talento y la reflexión personal, y las que se producen mediante el intercambio colectivo en la sociedad, como el arte o la educación. Se hace ver que para disfrutar bienes estimados individualmente se requiere del bien común, ya que la satisfacción de aspiraciones individuales implica la existencia de una comunidad en la que se den y se compartan. 
Damos por sentado que no existen opciones privadas para satisfacer todas las posibles demandas, sino que, por el contrario, se requiere acción colectiva, especialmente acción gubernamental para satisfacer ciertas demandas. Investigadores de diferentes orientaciones debaten el punto óptimo en que convendría colocar la frontera entre ambos tipos de provisiones. Dejaremos esa cuestión para abocarnos al estudio del papel que puede ocupar la ética en el proceso de análisis de las políticas públicas dirigidas a la elección racional de bienes públicos.

\section{La política como mecanismo generador de elecciones de política pública}

La acción colectiva y la negociación política son necesarias para que se llegue a acuerdos relativos a bienes socialmente deseados, así como a la organización y disposición de los recursos y el trabajo necesarios para su producción. No menos importante es la negociación política para acordar la forma en que los diferentes actores sociales disfrutarán de los bienes generados, por lo que se da en ambas facetas un esfuerzo político para obtener asignaciones y cargas de bienes privados y colectivos dirigidos a la realización del bien común. Las sociedades tienen que determinar, por la naturaleza de los bienes, si efectivamente la acción colectiva es el mejor medio para su producción, o si el bien admite su producción particular; entonces se requiere legitimar, por qué el conjunto asumirá una carga que no estaría obligado a tener. Estos procesos de negociación no garan- tizan que los acuerdos sean económicamente óptimos, ni tampoco que sean políticamente justos.

Con González Madrid considero que "las políticas públicas, en tanto acciones públicas producidas en sociedades democráticas, son una forma privilegiada de expresión de la decisión colectiva a partir de la articulación selectiva de una multiplicidad de intereses y preferencias valorativas"7.

El gobierno juega el papel de coordinador y árbitro del proceso político valiéndose de las instituciones públicas a fin de que se alcancen los acuerdos necesarios para la articulación de la producción y distribución de los bienes públicos. Los economistas definen el bien público (o bien social en este artículo) como aquel de "consumo colectivo perfecto", es decir, aquel que puede ser disfrutado por muchos o por todos, sin necesidad de dividirlo, ni de que alguien reciba una provisión mayor: "Ciertos bienes tienen la peculiaridad de que, una vez disponibles, no puede impedirse a nadie su disfrute, independientemente de que se contribuya a su provisión o no. Éstos son los bienes públicos. La ley y el orden constituyen un ejemplo y hay muchos otros tan familiares que no requieren mayores explicaciones. Su característica esencial es que se disfrutan pero no se consumen [y se derivan sus beneficios] sin ningún acto de apropiación”8.

En contraposición a esta definición que enfatiza la oferta, Steiner subraya el hecho de que se requiere de la acción colectiva para su producción, por lo que se requiere:

\footnotetext{
Miguel González Madrid, "Las coordenadas básicas de la decisión racional: Entre la libertad del actor y el determinismo contextual”, Políticas públicas en el nuevo sexenio, de J. M. Martinelli (México: UAM/ Plaza y Valdés, 2002) 21-22.

8 Robert Dorfman, “General Equilibrium with Public Goods” (1966). Citado en Peter Steiner, "El sector público y el interés público”, Un análisis del gasto y las políticas gubernamentales, de R. Haveman y J. Margolis (México: FCE, 1992) 20.
} 
“1) una diferencia apreciable, ya sea en cantidad o en calidad, entre ese bien y el que produciría el mercado privado; 2) una deman-

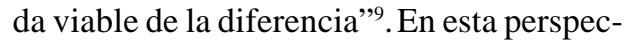
tiva es la demanda de bienes que no pueden ser satisfechos por iniciativas privadas, como por ejemplo las que requieren altas inversiones o que constituyen monopolios naturales, o las que no pueden ser vendidas óptimamente por el mercado (deseconomías externas).

Se hace ver el supuesto de que una provisión óptima a través del mercado es más deseable en cuanto que representa una mayor racionalidad ya en el aprovechamiento de los recursos como en el precio que los bienes adquieren. Sin embargo, se soslaya el hecho de que políticamente ciertos bienes no quieren ser dejados en control de ningún particular, ni a la "mano invisible”, dada la valoración social que se les ha conferido.

En virtud de que un serio limitante para que las elecciones públicas reflejen una perfecta racionalidad es el hecho de que son políticas, es decir, que se producen mediante el concurso político de personas con intereses y concepciones del bien diferentes, hecho que no puede resolverse mediante la regla de agregación. Kenneth Arrow veía en este modelo el riesgo de que se dieran preferencias cíclicas, que no se encontrarían en los individuos, por ejemplo cuando I prefiere A sobre B y B sobre C; II prefiere B sobre A y A sobre $C$, mientras que III prefiere $C$ sobre B y B sobre A. Al agregar estas preferencias se descubre que son cíclicas y no queda claro cuál debería ser la preferencia general. Problemas de este tipo son muy frecuentes, por ejemplo, cuando se impuso el denomi- nado corralito en la Argentina, impidiendo que los particulares retiraran sus depósitos de los bancos... una era la preferencia de los electores, otra la de los bancos, otra la del gobierno.

El debate político desafía a la racionalidad en cualquier etapa del policy process. En otras palabras, se nos exige estudiar tres problemas que enfrenta la realización del bien común con base en el contexto real en que se definen las políticas públicas (political public policies).

\section{Primera dificultad: la formulación de las políticas públicas}

Los autores debaten si la asignación de los bienes públicos es más adecuadamente representada por el juego político, el mercado, o bien por la cultura política y sus valores.

El primer enfoque sostiene que lo político se define porque corresponde a la discusión de intereses plurales, por lo que las decisiones y acciones -políticas (públicas)- son políticas por su origen, ya que surgen de la confrontación de grupos e intereses. La ponderación ocurre caso por caso, sostienen Dahl y Lindblom ${ }^{10}$, el ámbito público sirve para la discusión y decantación de versiones y objetivos rivales del bien. La legislación y los programas gubernamentales materializan los acuerdos vinculantes relativos a los bienes que se perseguirán mediante asignaciones públicas. En ese mismo sentido se manifiesta Theodor Lowi mediante su enfoque de arenas de política ${ }^{11}$. Para este autor, las polí-

9 Steiner, "El sector ...", 22.

10 Cf. Robert Dahl y Charles Lindblom, Politics, Economics and Welfare (Nueva York: Harper and Row, 1953).

11 Cf. Theodor Lowi, “American Business and Public Policy Case Studies and Political Theory”, World Politics XVI (1964). "Four Systems of Policy Analysis", The Future and the Past: Essays on Programs (Russell Sage Foundation, 1978). Citado en Aguilar, "Estudio ...”, 32-33. En el mismo sentido, Dorfman 
ticas públicas son resultado de la predominancia vinculada al poder de alguno(s) de los actores sociales para persuadir o imponer al conjunto sus propias prioridades. En las arenas existen rivalidades pero el conflicto aparece sólo en la medida en que son incompatibles los objetivos, esto es, cuando los recursos son insuficientes y tienen que ser redistribuidos, lo que implica sacrificar el interés de alguna(s) parte(s). El enfoque de Lowi no reconoce mayor legitimidad a la posición de las partes predominantes, ni se toma en cuenta la eticidad o compatibilidad de los objetivos de la parte con aquellos albergados por la sociedad política en su conjunto, dado que se sostiene con base en el supuesto democrático de que no existen razones que no sean las que se convienen mayoritariamente conforme a la regla de mayorías, donde la razón la tiene el (partido) más fuerte.

Es verdad que las políticas públicas resultan de acuerdos políticos a partir del debate respecto a los objetivos socialmente deseables, pero no ocurren meramente por el poder de las partes, sin tomar en cuenta el marco valorativo fundamental del estado o mandato a priori de políticas (ver infra). El enfoque exige no ser reducido como lo hace Lowi para mantener su validez y aplicabilidad.

Puede decirse que el partido en el poder es el depositario de una voluntad que le concede la prerrogativa de organizar y priorizar los bienes y objetivos públicos conforme a la información a su disposición y la agenda precontratada en su programa de acción. Puede pensarse, por otra lado, que se vale de su posición privilegiada para impulsar su propia agenda realizando o hipostasiando en las políticas públicas sus propios objetivos de poder.

Otra posibilidad es que el mercado permita resolver las necesidades sociales, ya sea mediante la provisión privada de bienes públicos, como por ejemplo a través de empresas de seguridad pública, de aguas o energía; o bien mediante un gobierno que funcione como cuasimercado, interpretando las preferencias colectivas y despachando las provisiones correspondientes. En la primera modalidad, son los agentes particulares los que concurren al mercado y mediante sus elecciones van indicando sus preferencias (reveladas), premiando o castigando a los proveedores según su desempeño. Un mercado que opere sin distorsiones y con suficiente acceso a la información, permitirá elevar los horizontes de eficiencia, por lo que los bienes son recibidos a un precio óptimo y en una cantidad óptima.

En este escenario quedan, sin embargo, sin respuesta los problemas derivados de las externalidades positivas, es decir, aquellos bienes para los cuales no es posible establecer barreras de ingreso, ya que están abiertos a todos, inclusive a aquellos que no estén pagando por ellos. Las externalidades positivas son áreas en las que es más ventajosa para el agente particular la no cooperación, pues éste espera que sean los demás quienes paguen sin que deje de recibir su parte. Este fenómeno de externalidades positivas, denominado por la literatura como del free raider o gorrón ${ }^{12}$, complicaría enormemente a una

se adhiere a la idea de que los grupos de presión socioeconómicos van modelando las agendas. Vid. Dorfman, "General Equilibrium ..."

12 Cf. M. Olson, La lógica de la acción colectiva (México: Limusa-Noriega, 1992). Cf. Steiner, "El sector ...”, 23ss. Las externalidades pueden deberse a condiciones técnicas de los bienes (el agua potable, su distribución requiere una infraestructura monopólica costosa), o a imperfecciones del mercado (el alumbrado público: ilumina a todos, paguen o no la luz), o a condiciones del ambiente (los parques o reservas nacionales, que ni son convertibles ni pueden ser consumidos libremente). 
entidad privada el proveer este tipo de bienes, por lo que siempre quedarían áreas imposibles de satisfacer óptimamente por el mercado.

El gobierno como cuasimercado se manifiesta mediante los votantes dispuestos a colocar más votos a favor de un proyecto de gobierno que satisface de manera más eficiente los intereses de los electores. El gobierno electo adquiere un poder discrecional para canalizar los recursos necesarios a fin de lograr determinados objetivos. Idealmente se instaura un mecanismo de principal y agente mediante el cual el gobierno opera como administrador de un mandato recibido por parte del electorado. Se establece entre principal y agente un contrato formal o informal, que adopta tres formas: relaciones jerárquicas (terrateniente, jornalero), relaciones igualitarias (los derechos y obligaciones se trasmiten de manera simultánea), relaciones temporales de subrogación de derechos de propiedad del principal al agente (concesión, franquicia, fideicomiso) $)^{13}$.

Las dificultades que entraña este modelo son múltiples. Por una parte, Steiner ${ }^{14}$ ve el riesgo de que los electores actúen de manera irresponsable al diluirse la responsabilidad por las consecuencias del voto emitido; debido a que el voto es indiscriminado, también se genera la inconsistencia de que aunque se prefiera a un partido, puede no estarse eligiendo la totalidad de sus postulados programáticos. Finalmente, se deja por fuera el hecho real de que los recursos son controlados por determinados actores sociales y no quedan automáticamente a disposición del partido ganador.
La tercera alternativa para la determinación de las asignaciones es el marco cultural y axiológico fundamental del Estado, al que me he referido como Mandato a priori de política $^{15}$. Con anterioridad a la existencia de cualquier gobierno particular, el Estado ya ha fijado ciertas metas fundamentales, ya ha reconocido ciertos valores indispensables, origen y destino de su propio proyecto como Estado. Tales metas son la precondición que determina cualquier política posible.

Supongamos como ideal un proceso donde, obedeciendo a un principio de racionalidad formal kantiana, se determinara a priori lo debido; luego se determinan empíricamente las características de un problema u objetivo social dado; y finalmente se formula la política que pretende resolverlo.

Tal definición a priori opera como una toma de postura de parte del Estado, como producto del convenio democrático fundamental de la sociedad (pacto social). Esa definición servirá como marco referencial a priori, aplicable a los problemas específicos presentados.

La idea de un mandato a priori de política nos dice que la sociedad desde sus bases culturales ya aprecia ciertos valores y principios, y que desde ellos construye la política práctica y configura al Estado. Estos valores son parte de lo que podríamos llamar cultura política y determinan cómo, por ejemplo, una sociedad aspira a la democracia, a la tolerancia o a la libertad como bases de toda ética política, ante las cuales se confrontarán las acciones concretas o políticas públicas. No obstante, también determinan que una

\footnotetext{
José Ayala Espino, Instituciones y economía (México: FCE, 2001) 155.

14 Cf. Steiner, “El sector ...”, 47-51.

15 Jesús Serrano, La naturaleza ética de las políticas públicas (México: Universidad Pontificia de México, 2001) 114.
} 
sociedad valore la corrupción, la disculpa o a la mediocridad como parte de sus políticas públicas... indicándonos en este caso una distorsión en la comprensión de la naturaleza de la sociedad y de lo público.

El Mandato a priori de política es una valoración que es dada para aquel que ocupa la posición de elaborar políticas. Esta valoración es de orden trascendental, dados los imperativos ontológicos que pesan sobre el Estado. Mediatamente consiste en la voluntad constituyente del Estado e inmediatamente se encuentra positivizada por la constitución y el régimen legal de cada Estado. El gobierno interpreta las demandas por bienes públicos a la luz de aquellos objetivos y valores superiores definidos a modo de limites e imperativos impuestos por el mandato $a$ priori.

\section{El utilitarismo como método principal para la elaboración de políticas públicas}

El utilitarismo configura el enfoque económico a tal punto que se justifica tomarlos como sinónimos. Según Becker, “Todos reconocen que el enfoque económico asume un comportamiento maximizador de forma más explícita y extensa que otros enfoques, sea que se maximice la función de utilidad o de riqueza del hogar, la empresa, sindicato u oficina gubernamental"16.

En la base del enfoque se encuentra la interpretación de Adam Smith respecto a la conducta del mercado, que tiende a equilibrios óptimos (la mano invisible) bajo la premisa básica de la economía, a saber, que se re- quiere aprovechar mediante la mejor asignación posible recursos escasos para satisfacer metas u objetivos en competencia. Según Jeremy Bentham, se trata del cálculo de placer y dolor: "La naturaleza ha puesto a la humanidad bajo el gobierno de dos amos soberanos: dolor y gozo. Es únicamente a ellos a quienes corresponde señalar lo que debemos hacer, así como determinar lo que haremos... nos gobiernan en todo lo que hacemos, en todo lo que decimos, en todo lo que pensamos" ${ }^{\prime 17}$.

El agente ético es necesariamente egoísta y el egoísmo es ético. No obstante, el utilitarismo concede exagerada importancia, incluso reduce su antropología al agente egoísta maximizador de utilidad (Homo aeconomicus). El egoísmo es una impronta de la conducta (ética), reconocido por Aristóteles en las bases metafísicoantropológicas de su Ética: el "bien es aquello a lo que todas las cosas aspiran”18. No hay acción que pueda efectuarse si no es con base en un bien conocido y apetecido por el agente. El agente reconoce el objeto como bueno en sí y para sí, y por eso le compromete su voluntad. Es en ese sentido no sólo un horizonte irrebasable, sino natural y propio del orden de la conducta ética.

La eticidad del utilitarismo individual o egoísmo se reconoce al relacionar la búsqueda de bienes de un individuo con la misma aspiración y derecho en varios individuos (bien social) y con todos (bien común).

El utilitarismo se ha extendido en la misma medida en que la economía capitalista ha impuesto como medida de asignación de valor la utilidad, y ésta ha sido convencio-

16 Gary Becker, “The Economic Approach to Human Behavior”, Rational Choice, de Jon Elster (Oxford: Basil Blackwell, 1986) 109-110.

17 Jeremy Bentham, An Introduction to the Principles of Morals and Legislation. Citado en Becker, "The Economic ...”.

18 Aristóteles, Ética a Nicómaco, Libro 1, capítulo 1. 
nalmente ponderada e intercambiada mediante el denominador precio. A pesar de su vigencia, el utilitarismo es estigmatizado como forma de conducta antiética, lo cual es inadecuado ${ }^{19}$. El egoísmo se convierte en antiético cuando la persecución del bien propio se realiza al costo del bien ajeno, cuestión que se pondrá de relieve, líneas más adelante, al analizar la aplicación de los principios de justicia en América Latina.

El utilitarismo, como método ético, se basa en el principio utilitarista que dice: el mayor bien o felicidad general. Para John Stuart Mill (1806-1873) esto implicaba que es moral perseguir el mayor bien, entendido como felicidad y placer a escala personal; y a nivel social el objetivo moral consiste en lograr el mayor bien para el mayor número de personas.

Muchos problemas y dilemas morales pueden ser rápidamente caracterizados por la necesidad de alcanzar y maximizar utilidad. Estas situaciones representan con frecuencia problemas morales, ya que la maximización representa dejar víctimas, al ser excluidos algunos del bien que se persigue, y es necesario justificar por qué algunos reciben y otros no, principalmente cuando se trata de bienes públicos que suponen la socialización de sus costos. Otra variante es el caso en que lo que unos ganan resulta a costa de otros.

En su obra ¿Qué es el utilitarismo?20. Mill manejaba esta concepción organicista de la sociedad, pensamiento que ha sido llevado a la consideración de los agregados sociales, es decir, a la medición consolidada de la uti- lidad/felicidad o el dolor/desutilidad sumando el total de una población. La situación en la que el bien común (el bien para el mayor número) representa el sacrificio de algunos no puede ser aceptada sencillamente como buena -aspecto que Mill soslaya por completo-; es necesario justificarla analizando qué bienes están en juego, qué proporción de costos y qué personas son las que pagan por el bien general.

Una de las estilizaciones extremas del utilitarismo es el supuesto de que los seres humanos, como entidades racionales, son capaces de tomar decisiones óptimas, sin percatarse de que tales decisiones requerirían el acceso a una información absoluta.

\section{Segunda dificultad: racionalidad y acceso a la información}

La información es la materia prima de las decisiones. La prudencia permite establecer juicios prácticos respecto a cómo maximizar el bien, pero esos juicios relacionan datos (información de los hechos actuales) con principios (reglas de decisión). Los métodos éticos se ocupan de las diversas maneras en que se puede realizar el juicio prudencial, los principios resultan de las exigencias inherentes a la ética particular aplicable y la información procede de las situaciones concretas de la vida de los agentes morales y constituye una economía de la información.

Le llamamos economía de la información ${ }^{21}$, en primer lugar, al hecho de que la información es un cierto tipo de bien que puede ser

19 Los economistas utilitaristas fallan al prescindir en sus análisis y modelos del problema de que no todos los bienes en un esquema psicológico moral de decisión, pueden reducirse a la abstracción de la utilidad, que en la teoría es sumamente abstracta y general. Los eticistas fallan al formular principios morales que no reflejan la importancia del egoísmo natural de los agentes, diseñados de manera ideal y tan abstractos como sucede en economía, pidiendo en el peor de los casos, que el agente actúe con independencia de su propio interés.

$20 \quad$ J. S. Mill, El utilitarismo (Buenos Aires: Aguilar, 1962) 3.

21 Se sugiere leer José Ayala Espino, Instituciones y economía (México: FCE, 1999) capítulo IV, 134-173. 
obtenido, producido e intercambiado, y que por lo tanto genera un "mercado de información” al cual concurren los agentes. En segundo lugar, ya que, como todo recurso, es escasa, la información tiene que ser administrada para obtener el mejor resultado de ella. Es ideal que las decisiones gocen de la máxima información posible, pero en caso contrario, las decisiones y el bienestar tienen que lograrse con la información que esté disponible.

La información es la parte de la descripción de la realidad que va a ser considerada importante para tomar una decisión. Revela, por lo tanto, quiénes son los agentes, qué intereses tienen y qué circunstancias los afectan a la hora de tomar sus decisiones.

Se esperaría que un agente racional sea capaz de tomar siempre las mejores decisiones, ya que entiende perfectamente cuáles son los bienes y cuál es el mejor de ellos ${ }^{22}$. En función de lo anterior, se puede prever qué ocurrirá, al anticiparnos al tipo de decisiones que tomarán los agentes en función de la información de que disponen y de las preferencias que conocemos tienen. Sin embargo, esto no ocurre así, ya que: 1 ) los agentes casi nunca poseen información perfecta y completa de la realidad; 2) aunque la conozcan, la complejidad y abundancia de la información es inmanejable para los agentes, quienes tienen que recortar y basarse sólo en una porción de la información que les resulte cómoda de manejar -a veces ese recorte es muy arbitrario, caprichoso e incluso compromete la moralidad del agente, quien decide a conveniencia y no con honestidad a sí mismo; 3) la información es asimétrica, o sea, unos la tienen mientras que otros no. Unos pueden así tomar mejores decisiones e inclusive usar su información en perjuicio de otros.

El sujeto toma sus decisiones con base en el bien conocido. Este conocimiento tiene que ser verdadero. Para alcanzar el nivel de veracidad se requiere de información suficiente y pertinente. Información y verdad no se identifican, pero mantienen una relación estrecha, ya que la primera debe conducir a la segunda, entendiendo como verdad la adecuación entre realidad (objeto) y término mental (idea). Dado que la ética asume la dimensión práctica de este problema, la decisión se toma en función del bien según es conocido.

A nivel práctico, no basta con que la información sea suficiente, sino que ésta tiene que ser efectivamente aplicable para tomar una decisión; se requiere entonces que sea pertinente al objeto. En este sentido es importante recordar la denuncia de Green: es posible que alguien crea que " 'si tenemos una metodología sofisticada y la información suficiente, entonces podremos responder cualquier dilema que se nos presente'. Quien piense así, comete un grave error, pues toma el dilema como un problema teórico y no como es, un problema práctico"23. En efecto, la verdad práctica no sólo se construye a partir de la verdad teórica, sino de su pertinencia efectiva para realizar el bien.

22 Este es el principal fundamento de la economía liberal o clásica. Considera que los agentes son perfectamente racionales y que eligen en condiciones de información perfecta. La teoría sostiene que un mercado con actores racionales e información perfecta permite las asignaciones óptimas... es decir, distribuye de la manera más eficiente, los recursos, los productos, asigna precios y permite el máximo beneficio general, lo que Adam Smith denominó "la mano invisible”. Si esto ocurriera, supuestamente habría un estado de prosperidad sin distorsiones. Ya que ni los agentes son perfectamente racionales, ni la información es perfecta, entonces se requiere todo tipo de compensaciones, desde subsidios, control de precios, leyes y reglamentos, así como oficinas públicas de información. Ver George Stingler, "The Economic of Information”, Journal of Political Economy 69 (1961).

23 Cf. Thomas Green, “Policy Questions”, Education Policy Analysis Archives, II. 7 (1994). 
CUADRO 1

Aplicabilidad del conocimiento

\begin{tabular}{|c|c|c|c|}
\hline \multicolumn{2}{|c|}{} & Adecuado Pertinente & Inadecuado Impertinente \\
\hline Información & Insuficiente & $\begin{array}{c}\text { Incertidumbre/ Incompleta y } \\
\text { perfecta }\end{array}$ & $\begin{array}{c}\text { Duda/ Incompleta e } \\
\text { imperfecta }\end{array}$ \\
\cline { 2 - 4 } & Suficiente & Verdad/ Completa y perfecta & $\begin{array}{c}\text { Equívoco/ Completa e } \\
\text { imperfecta }\end{array}$ \\
\hline
\end{tabular}

Como se ve en el cuadro (cuadro 1), el conocimiento puede ser pertinente a la solución del problema ético o sencillamente ser ajeno al caso. Eso no afecta la veracidad de la información en sí -ya que no es un problema teórico-, sino su capacidad para realizar el bien -pues es un problema práctico.

La economía neoinstitucional subraya el hecho de que la información accesible al agente puede o no ser suficiente. Sin embargo, no considera algunas variantes:

Puede ser que tengamos necesidad de actuar, a pesar de que la información sea insuficiente. Esto puede ser subóptimo pero no es antiético. Más aun, puede ocurrir que la información insuficiente constituya una duda, lo que nos impide actuar, pues hacerlo no sólo sería subóptimo, sino también antiético. El criterio nos dice que en caso de duda no se puede actuar sin primero resolver el objeto de duda, a menos que sea imperativo, en cuyo caso hay que seguir el camino más seguro (o maximin).

Aun en el caso en que dispongamos de información suficiente, puede ocurrir que esté siendo aplicada de manera impropia a un caso u objeto con el cual no se corresponde. Se trata entonces de un equívoco práctico.
"La base informacional de un juicio identifica la información de la que depende directamente el juicio y -no menos importante- establece que la verdad o falsedad de cualquier otro tipo de información no puede influir directamente en la rectitud del juicio. La base informacional de los juicios de justicia determina, pues, el territorio fáctico al que las consideraciones de justicia se aplicarán directamente. (Las implicaciones sobre otros asuntos serían indirectas.)”24.

La situación en la que se cumplen las condiciones de información suficiente y pertinente, la denominamos verdad práctica.

Con los elementos presentados hasta aquí, podemos establecer que la racionalidad se refiere a: a) decisiones o acciones de b) personas, grupos u organizaciones, quienes eligen c) de entre un ordenamiento de preferencias o cursos de acción, con base en d) metas, deseos y creencias, e) bajo las reglas de no contradicción, consistencia, transitividad y reversibilidad ${ }^{25}$.

En su Teoría de la justicia, John Rawls (1921-2002) manifestaba su preocupación por el sesgo que imponía el utilitarismo a las decisiones públicas. La mejor forma de definir la propuesta de sus principios de justi-

A. Sen, Bienestar, justicia y mercado (Barcelona: Paidós, 1997) 109.

25 Cf. González Madrid, “Las coordenadas ...”, 27. 
cia es el intento por resolver el dilema entre eficiencia y justicia, entre la necesidad de un sistema económico expansivo regido simultáneamente por la regla de maximización de utilidades y minimización de costos, lo que implica en el Estado la desigualdad distributiva y el empeño por lograr condiciones mínimas de bienestar a partir de la igualdad en la abstracta noción liberal de libertad, y la regla de que mayores beneficios para unos sólo se justifican si vienen acompañados de mayores beneficios para los menos aventajados, cumpliendo con el óptimo de Pareto en la distribución.

Vilfredo Pareto ${ }^{26}$, sociólogo francés, radicado en Italia y muerto en Ginebra, sostenía que es óptima una distribución en la que ninguno de los agentes pueda ganar algo sin que al mismo tiempo otro agente pierda algo.

John Rawls propuso que la desigualdad podría y debería ser un mecanismo de bienestar social, bajo dos restricciones: una es que se cumpliera el óptimo de Pareto, y la otra, que se aplicara el criterio maximin para seleccionar entre diferentes distribuciones posibles.

El problema al aplicar el óptimo de Pareto es saber si efectivamente hay un equilibrio tal que, si se alterara, algunos pudieran resultar beneficiados mientras otros empeoraran. Esa y otras circunstancias podrían inmovilizar la toma de decisiones por el temor de marginar a algunas personas, así que Rawls formula la regla maximin para elegir en situaciones de incertidumbre: "La regla maximin nos dice que debemos jerarquizar las alternativas conforme a sus peores resul- tados posibles: habremos de adoptar la alternativa cuyo peor resultado sea superior al peor de los resultados de las otras alternativas" ${ }^{27}$.

Por ejemplo, sean tres sociedades A, B y C, con las distribuciones siguientes:

$\mathrm{A}(5,4,5,7), \mathrm{B}(5,6,3,8)$ y $\mathrm{C}(9,8,2,4)$

La mayor utilidad para la mayoría, es decir el mejor resultado utilitarista es $C$, ya que $\mathrm{C}(23)>\mathrm{B}(22)>\mathrm{A}(21)$, pero el criterio maximin nos pide elegir aquella sociedad en que la peor parte, el más pobre, esté mejor en comparación con otras distribuciones, por lo que se elegirá $\mathrm{A}$, a pesar de que no representa la máxima utilidad posible.

Como método, la regla maximin se aplica para tomar una decisión en situaciones de incertidumbre. Muchos problemas morales se resolverían -o sencillamente nunca aparecerían-si contáramos con una información plena respecto a un hecho, sus causas, sus consecuencias, etc. Como en la inmensa mayoría de los casos nos falta información, y -como en las restricciones del Principio de Doble Efecto- es peor o imposible dejar de actuar, entonces requerimos de una regla para minimizar el mal o, más propiamente, para asignar adecuada y legítimamente las cargas en la distribución.

Supongamos, para ilustrar estas reflexiones, que comienza a presentarse un brote epidémico en la ciudad ${ }^{28}$. La población está ampliamente alarmada; sin embargo, las autoridades están respondiendo para “cercar” la población afectada, que será de 600 personas.

26 Cf. V. Pareto, Transformazione della democrazia (Milán: Corbaccio, 1920). Ver también sobre otros aspectos de la propuesta José Luis Orozco, Pareto: Una lectura pragmática (México: Fontamara/ UNAM, 1997). Sobre su biografía, ver pág. 11; sobre la búsqueda de la mayor utilidad colectiva, págs. 93-98; sobre la desigualdad y la concentración, pág. 99; sobre el efecto concentrador y el óptimo, pág. 136-137.

27 J. Rawls, Teoría de la justicia (México: FCE) 181.

${ }_{28}$ Ficción inspirada en el ejercicio de Amos Tversky y Daniel Kahneman, "The Framing of Decisions and the Psychology of Choice”, en Rational ... de Elster, 123-125. 


\section{CUADRO 2}

\section{Cálculo de probabilidades}

\begin{tabular}{|c|c|c|c|}
\hline & Se salvan & Mueren & \\
\hline Tratamiento A & 200 & 400 & Certeza \\
\hline Tratamiento B & 400 & 200 & Probable, pero no real \\
\hline
\end{tabular}

Existen dos tratamientos para combatir la enfermedad. En virtud de la evidencia científica que se ha probado hasta la fecha pueden esperarse los siguientes resultados para los dos tratamientos:

Si se adopta el tratamiento A, 200 personas se salvarán.

Si se adopta el tratamiento B, hay una probabilidad de $1 / 3$ de que 600 personas se salven (optimista). Pero hay una probabilidad de $2 / 3$ de que nadie pueda salvarse (pesimista).

Virtualmente existe un tratamiento C, que consiste en no hacer nada, con lo cual se asegura la muerte de 600 personas.

¿Cuál de los tres programas debe adoptarse? Están en juego los siguientes resultados:

Por una parte, con el tratamiento A aseguramos la muerte de 400 y la salud de 200 personas.

Por otra, con el tratamiento B hay riesgo de que mueran 600 (2/3), al multiplicarse, 400. $\mathrm{Y}$ la esperanza de que se salven $600(1 / 3)$, al multiplicarse, 200.
Si se suman los resultados en cada hilera, descubrimos que ambas opciones son equivalentes en términos agregados, es decir, que maximizan la utilidad, y cumplen con ello el principio de Mill, "el mayor bien general". Sin embargo, una reflexión sensata nos dice que estos resultados no pueden ser agregados, que las sumas promedio no pueden ser aceptables en sí mismas, sin tomar en cuenta las personas concretas que serían afectadas.

Dado que nuestra elección se realiza en condiciones de incertidumbre, podemos invocar la regla maximin según la cual entre los dos tratamientos el pago mínimo (la peor parte) en el tratamiento A es la muerte de 400 personas.

En el tratamiento B, el pago mínimo es la muerte de 600 personas. Por lo que se preferiría el tratamiento A, que garantiza la sobrevivencia de 200 personas, sin riesgo. Esta decisión busca asegurar el interés moral con base en el análisis realista de las posibilidades de manera informada y manejando la incertidumbre en beneficio de la parte más débil. Tenemos un intento -sin discutir por el momento su solidez- de resolver el impasse entre racionalidad y justicia, entre utilidad y distribución ${ }^{29}$.

29 El caso guarda, al menos en su enfoque "ético", una extraña semejanza con el protocolo ACTG 076, de los Institutos Nacionales de Salud de los Estados Unidos (NIH), que se revelaron en el New England Journal of Medicine de septiembre de 1997. Como parte de una investigación en Africa (Etiopía), se venía aplicando el retroviral zidovudina a mujeres embarazadas, infectadas con el VIH-SIDA. El objetivo era disminuir la transmisión del VIH de madres a hijos, pero optimando los costos de este tratamiento aplicando dosis con cierto espaciamiento. A toda la población seleccionada se le aplicaban inyecciones con la misma periodicidad, pero algunas de las dosis eran placebo de modo que las receptoras no sabían cuáles eran el retroviral o con 


\section{Tercera dificultad: los efectos distributivos y redistributivos}

En la primera sección de este artículo se ha justificado la importancia y papel que juega la ética en el diseño de políticas públicas en virtud de los bienes públicos necesarios para la realización del bien común. En la segunda sección se ha puesto de relieve la centralidad del problema de la distribución como la dimensión propiamente política (y ética, en consecuencia) de las políticas públicas. El objetivo de eficiencia, es decir, de maximización de la utilidad nunca puede excluirse de nuestras consideraciones; sin embargo, la distribución requiere valerse de algunos principios de justicia, hecho que, según explica Jon Elster ${ }^{30}$, implica la posibilidad de valerse de diferentes procedimientos o métodos para la aplicación de dichos principios.

En esta última sección, de análisis y reflexión de la realidad latinoamericana, queremos exponer modalidades de aplicación de los principios de justicia, en la versión de John Stuart Mill, John Rawls y de Amartya Kumar Sen, evaluando en primer lugar la verificabilidad de su aplicación en América Latina, durante el periodo 1990-2002 para el caso de los dos primeros autores, y de las políticas de compensación al ajuste estruc- tural mediante el gasto social, conforme al tercero.

De acuerdo con Mill, el principio de utilidad o de mayor felicidad exige no sólo el mayor bienestar personal, sino el mayor bienestar general considerando la virtud ${ }^{31}$. En este punto, dada su concepción organicista de la sociedad, el principio utilitarista confía en la posibilidad de totalizar el bienestar mediante una medida agregada de utilidad. Este indicador es revelado de manera consistente mediante el ingreso per capita (IPC), que divide el producto nacional bruto (PNB) entre la población del país. Mill aceptaría que si entre dos tiempos, a valores actualizados, ha habido un mejoramiento del IPC, se pone de manifiesto que se está mejorando el mayor bien o utilidad general.

Se constata que el IPC de América Latina ha crecido un 9\% en el periodo 1990-2002, como se ve en el cuadro 3, por lo que se cumple el interés de Mill de que "el fin último por razón del cual son deseables todas las otras cosas (indiferentemente de que consideremos nuestro propio bien o el de los demás) es una existencia exenta de dolor y abundante en goces, en mayor grado posible, tanto cuantitativa como cualitativamente"32.

qué periodicidad se les estaba aplicando. La justificación que dieron las autoridades, Harold Varmus, director de los Institutos Nacionales de Salud y David Satcher, director del Centro para el Control de Enfermedades (Center for Disease Control) de este atentado a los derechos humanos y a la ética médica fue que el estudio era justo ya que "no se sabía de antemano" qué personas serían las beneficiadas y cuáles no" ya que "resultaba al azar". Ver: David M. Studdert y Troyen Brennan, "Clinical Trials in Developing Countries: Scientific and Ethical Issues”, The Medical Journal of Australia (1998) <http://www.mja.com.au>

30 Jon Elster, Justicia local (Barcelona: Gedisa, 1994) 77.

31 Cf. John Stuart Mill, Utilitarianism (Kitchener: Batoche Books, 2001) 14.

32 Mill, El utilitarismo, 36-37. En una versión más completa el modelo ha sido expuesto por Vickrey y Harsanyi, según expone Sen: como principio de eficiencia el objetivo es maximizar la función $\Sigma_{i} p_{i} W_{i}$ donde la función $\Sigma_{i}$ es la sumatoria de las utilidades $W_{i}$ de todos los individuos $i$, tomando como principio distributivo que todos los individuos tienen acceso a una misma probabilidad $p_{i}$ de ser cualquiera. W. S. Vickrey, “Measuring Marginal Utility by Reactions to Risk”, Econometrica XIII (1945), 601-707; Harsanyi, "Cardinal Welfare, Individualistic Ethics and Interpersonal Comparisons of Utility", Journal of Political Economy LXIII (1955) 309-321. Citado en Sen, Bienestar ..., 71. 
CUADRO $3^{33}$

Dinámica del ingreso per capita, la pobreza y la desigualdad en América Latina 1990-2002 (5 países)

\begin{tabular}{|c|c|c|c|c|c|c|}
\hline País & Año & IPC & $\Delta \%$ IPC & $\%$ Pobl. pobre & $\Delta \%$ P.P. & Gini $^{34}$ \\
\hline \multirow[t]{2}{*}{ Argentina } & 1990 & 5293 & & 21,2 & & 0,501 \\
\hline & 2002 & 6000 & 12 & 41,5 & 49 & 0,590 \\
\hline \multirow[t]{2}{*}{ Brasil } & 1990 & 3691 & & 48 & & 0,627 \\
\hline & 2001 & 4057 & 9 & 37,5 & -28 & 0,639 \\
\hline \multirow[t]{2}{*}{ Colombia } & 1991 & 2108 & & $52,5^{\mathrm{a}}$ & & 0,531 \\
\hline & 2002 & 2254 & 6 & 50,6 & -4 & 0,575 \\
\hline \multirow[t]{2}{*}{ México } & 1989 & 3853 & & 47,7 & & 0,536 \\
\hline & 2002 & 4754 & 19 & 39,4 & -21 & 0,514 \\
\hline \multirow[t]{2}{*}{ Venezuela } & 1990 & 3256 & & 39,8 & & 0,471 \\
\hline & 2000 & 2992 & -9 & 48,6 & 18 & 0,5 \\
\hline \multirow{2}{*}{$\begin{array}{l}\text { Promedio } \\
5 \text { países }\end{array}$} & 1990 & 3640 & & 41,8 & & 0,533 \\
\hline & 2000 & 4011 & 9,3 & 43,5 & 3,9 & 0,564 \\
\hline
\end{tabular}

Fuente: CEPAL.

a 1994.

El enfoque de Mill implica: 1) no es más relevante si se consigue el propio bien o el de los demás, 2) el mayor grado de utilidad cuantitativa es necesario para 3) disfrutar de tanto goce y ausencia de dolor como sea posible.

En América Latina se promueve 1) el crecimiento de la economía como un fin primario; 2) suponiendo, como sostiene la economía neoclásica, que las asignaciones tenderán al paso del tiempo a beneficiar a toda la población, como resultado de la racionalización progresiva; 3) el mayor acceso a recursos y riqueza permitirá una mejor satisfacción de las necesidades y la realización de las formas de vida estimadas por los individuos. Constatamos, entonces que se cumplen las condiciones previstas por Mill, para calificar como justa la política macroeconómica seguida en América Latina durante la década de los noventa ${ }^{35}$.

33 Comisión Económica para América Latina y el Caribe (CEPAL), sobre la base de información oficial de los países. CEPAL, Panorama social de América Latina 2004, Santiago de Chile 2004, LC/L.2220-P/E. Disponible para consulta en <http://www.cepal.org>

34 El coeficiente de Gini es una medida estadística de la desigualdad de una distribución. Si la variable está equitativamente distribuida, el índice tiende a cero, y si hay total concentración, tiende a uno. Un mayor coeficiente de Gini indica mayor desigualdad.

35 No puede dejar de observarse que estos tres supuestos son irreales ya que el 2) sostiene un proceso de optimalidad progresiva (efecto de derrama o trickle down) que, como ha sido demostrado, no ocurre por sí mismo, sino que requiere de la acción redistributiva por parte del gasto público (ver supra); por su parte el 
John Rawls percibió la necesidad de estructurar la política social de tal forma que no se cuestionara la racionalidad de los agentes económicos pero se reconociera la relevancia de un acuerdo distributivo que permitiera vencer la simplista fórmula utilitarista, como estableció mediante sus dos principios de justicia: de igualdad de libertades y de la diferencia ${ }^{36}$.

El gozne que permite articular, entonces, el principio de eficiencia utilitarista con el de justicia distributiva es el "óptimo de Pareto".

Numerosos especialistas, como Joseph Stiglitz ${ }^{37}$, han venido denunciando el proceso de concentración de la riqueza en América Latina. Esto significa, independientemente de que sí se esté generando riqueza, como lo manifiesta el crecimiento del IPC, que se está dando simultáneamente un proceso de redistribución tal que los miembros menos aventajados de la sociedad están desplazando riqueza a los sectores más favorecidos. Esto es cierto en general para el continente, mas no de la misma forma para todos los países. Si consideramos Argentina, su ingreso per capita pasó de 5293 a 6000 dólares, es decir, creció $19 \%$. Al mismo tiempo, la pobreza creció un $49 \%$ y la desigualdad pasó de 0,5 a 0,59 Gini. Si tomamos en cuenta a los cinco países seleccionados, su ingreso per capita pasó de 3640,2 a 4011,4 dólares, es decir, creció 9,3\%. No obstante, la pobreza creció un 3,9\%, y la desigualdad pasó de 0,5332 a 0,5636 Gini. Por lo tanto, concluimos que la distribución de la riqueza en América Latina (al menos para los países seleccionados) no es óptima, conforme a Pareto.

Conforme a los principios de justicia de John Rawls, [primer principio] "cada persona ha de tener derecho igual al esquema más extenso de libertades básicas que sea compatible con un esquema semejante de libertades para los demás”38, [segundo principio] "las expectativas más elevadas de quienes están mejor situados son justas si y sólo si funcionan como parte de un esquema que mejora las expectativas de los miembros menos favorecidos de la sociedad"39. Los datos nos permiten establecer, dando por supuesto que se cumple la condición del primer principio, que el ingreso per capita ha crecido para todos los sectores sociales, pero ha generado una transformación proporcional en la participación del ingreso, de modo que en el año 2002, el decil más alto en ingreso (el 10\% más rico), recibe en Brasil 32 veces el ingreso que reciben los sectores menos favorecidos (el 40\% más pobre). La relación es de 25 veces para Colombia, 20 veces en Argentina, 15 veces en México y 14 en Venezuela ${ }^{40}$.

3) no da cuenta del hecho de que la generación de riqueza requiere como condición su concentración con fines de generar economías de escala. El supuesto 3 implica per se que no puede haber justicia social conforme a los principios de Rawls. Agradezco la observación de Elizabeth Judd Moctezuma para refinar este planteamiento.

36 Téngase presente que las reacciones críticas al utilitarismo, que cobrarían forma y fuerza posteriormente, le deben al debate con Robert M. Hare, uno de los principales exponentes del utilitarismo norteamericano contemporáneo, y a la participación en un seminario conjunto en la Universidad de Harvard en los años 1968-69 de los destacados pensadores Kenneth Arrow, John Ralws y Amartya Sen.

37 Joseph Stiglitz, Whiter Reform? Towards a new agenda for Latin America, Segunda Conferencia de la Cátedra Raúl Prebisch, Santiago de Chile, 26 de agosto de 2002. Disponible para consulta en <http:// www.cepal.org>

38 Rawls, Teoría ..., 67.

39 Rawls, Teoría ..., 80-81. No debe perderse de vista el segundo principio en sus dos formulaciones: pág. 68 y especialmente pág. 88: subdividido en los principios de eficiencia y diferencia.

40 CEPAL, Panorama ..., 43 (Gráfico I.9). 
Constatamos nuevamente que, si bien se cumple con la premisa del principio utilitarista, no se cumple la condición del segundo principio de justicia de Rawls. Por lo tanto, la distribución de la riqueza en América Latina es injusta.

Si, como dijimos anteriormente, las políticas públicas se proponen como medios para alcanzar determinados bienes socialmente necesarios, entonces la situación en la que la magnitud de la pobreza no cede, ni la distribución es equitativa, exige aplicar medidas correctivas. La economía política, alimentada por las consideraciones de la ética política, propone objetivos normativos, como lo son la equidad y la justicia social. El análisis de políticas públicas tiene que partir de objetivos hechos explícitos, que serán sometidos a escrutinio.

Sea o no explícito, de la constatación de que la distribución es injusta y no es óptima se siguen acciones redistributivas. Sin duda, podrán darse explicaciones e interpretaciones diferentes, pero, ya sea porque se considere que se están corrigiendo fallas del mercado, o porque se está respondiendo a la presión de grupos políticos, o porque se esté cumpliendo una responsabilidad moral del Estado dado su mandato a priori, el hecho es que en América Latina se aplican de manera sistemática acciones redistributivas mediante el gasto social (cuadro 4).

Las políticas redistributivas por vía del gasto social no han revertido el efecto empobrecedor, pero sí han contribuido ligeramente a contrarrestar la pobreza. Las políticas redistributivas están siendo definidas en función de la administración de bienes para el bien común, sin importar cuál de las tres líneas explicativas se quiera utilizar.

Por efecto entendemos "la manera en que los beneficios y los costos del programa se distribuyen entre la gente, es decir; quién se beneficia y quién paga"41. Si se estima que en virtud de la justicia es necesaria la redistribución de la riqueza, entonces se tiene que reconocer que hay un costo social y que éste tiene también que ser asignado, lo que intuitivamente suele cargarse en la clase más privilegiada mediante un sistema impositivo progresivo -lo que no siempre ocurre, como es el caso de la Argentina, donde el sistema fiscal es altamente regresivo. Nicholas Kaldor y R. Hicks sostienen "que un cambio de la asignación de los recursos debería considerarse incrementador del bienestar si satisface el criterio de Pareto o las personas que han ganado con la asignación de los recursos podrían compensar a los que han sido perjudicados por ella, de modo que su situación sea por lo menos tan buena como habría sido sin la reasignación”42.

Desde dentro del enfoque utilitarista, los fondos disponibles a ser redistribuidos generarían dos escenarios, el original $A$, en el que los recursos están siendo asignados de manera inequitativa, y $A^{*}$ en que se introduce la distribución. ¿Es mejor la eficiencia agregada en $A^{*}$ que en $A$ ? Si el balance es negativo, entonces se preferiría el estado original $A$, o si el costo de transacción de la política redistributiva (la implementación de los servicios públicos) fuera tan costosa que restara eficiencia al sistema ${ }^{43}$.

\footnotetext{
41 Robert Haveman y Burton Weisbrod, "Definición de los beneficios de los programas públicos: Algunas directrices para los analistas de políticas”, Un análisis ..., de Haveman y Margolis, 108.

42 Haveman y Weisbrod, "Definición ...." 109.

43 Cf. Haveman y Weisbrod, "Definición ...” 110-119,
} 
CUADRO $4^{44}$

Gasto público social (GPS) en América Latina 1990-2000 (5 países)

Fuente: CEPAL

Estas desconcertantes conclusiones invitan a reflexionar más profundamente en esta problemática.

El gasto social se compone de las transferencias gubernamentales mediante bienes ("servicios”) públicos dirigidos a la sociedad, pero especialmente a los sectores más pobres. Para éstos se convierte entonces en un complemento a su ingreso, que procede de los bolsillos de sectores más ricos, que pagan impuestos, lo que tiende a "igualar" en alguna medida sus condiciones. El gasto social comprende educación (tres niveles), salud, nutrición, vivienda y servicios básicos de agua y saneamiento.

Lo que nos dicen las cifras de gasto social en América Latina, para el periodo 1990-1999,

\begin{tabular}{|c|c|c|c|c|}
\hline $\begin{array}{l}\text { País } \\
\text { es que }\end{array}$ & $\begin{array}{l}\text { Año fiscal } \\
\text { iste la decisi }\end{array}$ & 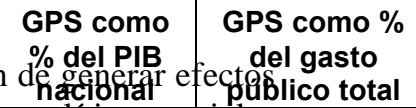 & $\Delta \%$ & $\begin{array}{l}\text { Transfe } \\
\text { per cal } \\
\text { dóla }\end{array}$ \\
\hline \multicolumn{5}{|c|}{ 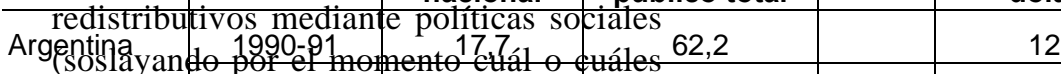 } \\
\hline de los & mectorisinos & generąllores de polí- 63,6 & 2,2 & 20 \\
\hline \multicolumn{5}{|c|}{ Brabifas sea el quggdegina estos ebjetivos), que 48,9} \\
\hline se está & estinandome & ores rę,yrsos públi- 60,4 & 19 & 10 \\
\hline \multicolumn{5}{|c|}{ 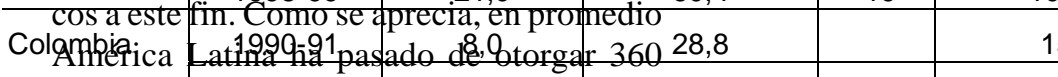 } \\
\hline \multicolumn{3}{|c|}{ 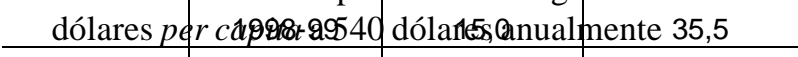 } & 18,9 & \\
\hline \multicolumn{4}{|c|}{ 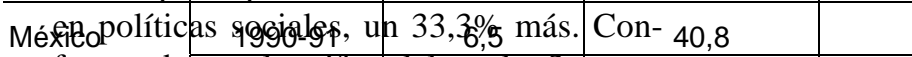 } & \\
\hline \multicolumn{3}{|c|}{$\begin{array}{l}\text { frontando, con las cifras del cuadro } 3 \text { yemos } \\
1998-99 \\
\text { que el gasto social no ha contrarrestado la } 58,5\end{array}$} & 30,3 & \\
\hline \multicolumn{3}{|c|}{ Vepörtedza y la Hesiggialdad, por 918 que se po- 34,0} & & \\
\hline \multicolumn{3}{|c|}{ 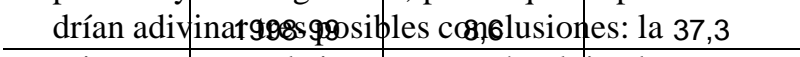 } & 8,8 & \\
\hline \multicolumn{4}{|c|}{$\begin{array}{l}\text { Propfiédora es q499o-gistema se está volviendo } 41,8 \\
\text { más ineficiente como resultado de la }\end{array}$} & \\
\hline \multicolumn{3}{|c|}{ 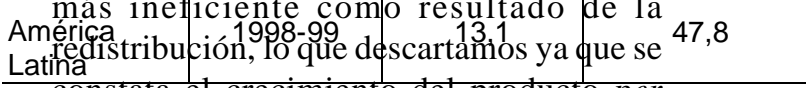 } & 12,6 & \\
\hline
\end{tabular}

44 Comisión Económica para América Latina y el Caribe (CEPAL), sobre la base de información oficial de los países. CEPAL, Panorama social de América Latina 2000-2001, Santiago de Chile, 2001, 117-118. Disponible para consulta en <http://www.cepal.org > 
capita; segundo, puede ser que los recursos hayan sido insuficientes para generar el efecto buscado; o, finalmente, puede ser que el mecanismo redistributivo sea regresivo en lugar de progresivo, por lo que el mismo financiamiento del gasto social se hace a costa de los sectores marginados, ocurriendo una transferencia en beneficio de los más pudientes $^{45}$.

Haveman y Weisbrod se cuidan de distinguir el enfoque meramente utilitarista (agregado) o efecto pecuniario, del efecto real: "Todos los efectos de bienestar, 'quienquiera que sean los beneficiarios', son pertinentes para una evaluación de los beneficios de los proyectos, pero es importante reconocer que algunos efectos (los efectos pecuniarios) sirven sólo para redistribuir el bienestar económico, mientras que otros (efectos reales) expanden las oportunidades del bienestar económico agregado"46. En esto se entronca esta reflexión con la preocupación de Amartya Sen de no sólo considerar los efectos de eficiencia económica, ni sólo los de disfrute de bienestar (mediante bienes y servicios públicos), sino la posibilidad de elegir formas de vida valiosas para el sujeto o libertad de opción ${ }^{47}$.

\section{Tareas}

Las posibilidades que se abren a la filosofía política gracias al empleo del análisis de políticas públicas permiten tanto revolucionar en buena medida tanto la comprensión que hacemos los filósofos de la realidad, como aportar elementos normativos como respuesta a necesidades vinculadas con principios éticos sustantivos.

La posibilidad de visualizar de manera concreta la aplicación de los principios de justicia social, en las versiones de Mill, Rawls y Sen, en América Latina, pone de relieve el hecho de que los objetivos de crecimiento y eficiencia económica son condiciones necesarias pero no suficientes para un estado de justicia y bien común. Las acciones redistributivas no están generando los efectos deseados, ni en su magnitud ni en su dirección, lo que exige una seria reflexión, sobre todo para los economistas positivos y para los administradores públicos respecto a las políticas públicas que se vienen practicando en el continente. Finalmente, se aprecia la necesidad para los eticistas y filósofos políticos de pasar a refinamientos normativos respecto a los principios adecuados a las necesidades sociales que permitan una mayor especificación y efectividad en sus propuestas, tomando en cuenta la exigida interdisciplinariedad de esta tarea. Desde el punto de vista metodológico, se percibe la necesidad de trabajar en un desarrollo de aquellos métodos que permitan un análisis ético de las políticas públicas, tarea que requiere una lectura de los clásicos. Casi nada impide que en el futuro podamos continuar desarrollando estas líneas.

45 Véase a tal efecto el trabajo de Juan Gómez Sabaini, Juán José Santieri y D. A. Rossignolo, La equidad distributiva y el sistema tributario: Un análisis para el caso argentino (Santiago de Chile: Instituto Latinoamericano y del Caribe de Planificación Económica y Social -ILPES-, 2002). El trabajo no sería tan impactante si los autores fueran otros que Gómez Sabaini quien fue Subsecretario de Política Tributaria y Santieri, quien fue Vicepresidente del Banco Central de Argentina.

46 Haveman y Weisbrod, "Definición ...”, 122.

47 Cf. A. Sen, “Capacidad y bienestar”, La calidad de vida, de M. Nussbaum y A. Sen (México: FCE, 1996) 54-83. 